\title{
A Data Mining Approach to Examine the Effect of Climate Change on the Growth of Pinot Noir Grapes in Western Oregon Using Machine Learning Methods
}

\author{
Student: $\underline{\text { Abhigya Sodani, Mentor: Debbie Cooper }}$ \\ Westview High School, $9^{\text {th }}$ Grade
}

\begin{abstract}
Student email: abhigyasodani@gmail.com, Mentor email: rocknpharaohs@gmail.com
\end{abstract}
\section{$\underline{\text { Abstract }}$}

The wine industry is one of the top industries in Oregon, with over 700 wineries in the state. This is why this study aims to find the effect of climate change on the wine industry in Western Oregon. To find this, I had to choose a specific grape to look at. The chosen grape was Pinot Noir because a large part of Oregon's wine revenue is from the sale of Pinot Noir wine. Also, I looked at Western Oregon specifically in this study because most of the wineries in Oregon are in Western Oregon. Using NASA's Giovanni website, the surface temperature data of Western Oregon was collected in the form of color-coded heat maps. Using these heat maps, the average surface temperatures during the growing seasons from 1979 to 2015 were found. The growing season for Pinot Noir is April to September. Then, using the average surface temperature data I found the average area of land that was in the ideal temperature range for ripening Pinot Noir for each specific growing season. Next, I got Oregon's average annual temperature data from NOAA's Climate at a Glance website. Using a machine learning regression method called LOESS I examined the two data sets and was able to derive insights from them. The data showed that, generally, as the average annual temperature rises, the average area of land that has a temperature suitable for ripening Pinot Noir decreases. Also, the data shows that the best average annual temperature for growing Pinot Noir is 47 degrees Fahrenheit. Lastly, the data from NOAA's Climate at a Glance website showed that Oregon's average annual temperature is increasing. This means that as time goes on, the area of land with a suitable temperature for growing Pinot Noir will gradually decrease.

\section{Introduction and Research Question}

Oregon wineries made 100 million dollars in the 20152016 fiscal year [8]. A large part of that revenue is from the sale of Pinot Noir. This is why one of the large impacts of climate change in Oregon will be on wine, and this impact will be both economical and agricultural. Therefore, the aim for this research project is to find out how climate change will affect the Pinot Noir grape growth in Western Oregon. This will be achieved by using data from NASA's Giovanni website and data from the NOAA (National Oceanic and Atmospheric Administration).

\section{Background Information}

Literature Survey about Oregon Wine:

Oregon has over seven hundred wineries across the state [4]. These wineries are scattered all over the state, but the majority of them are in Western Oregon because Western Oregon has the right conditions and soil types to grow wine grapes. In fact, the Willamette Valley (which is in Western Oregon) has 74\% of Oregon's vineyards [1]. Figure 1, which is pictured below, shows all the AVAs (American Viticultural Area) in Oregon.

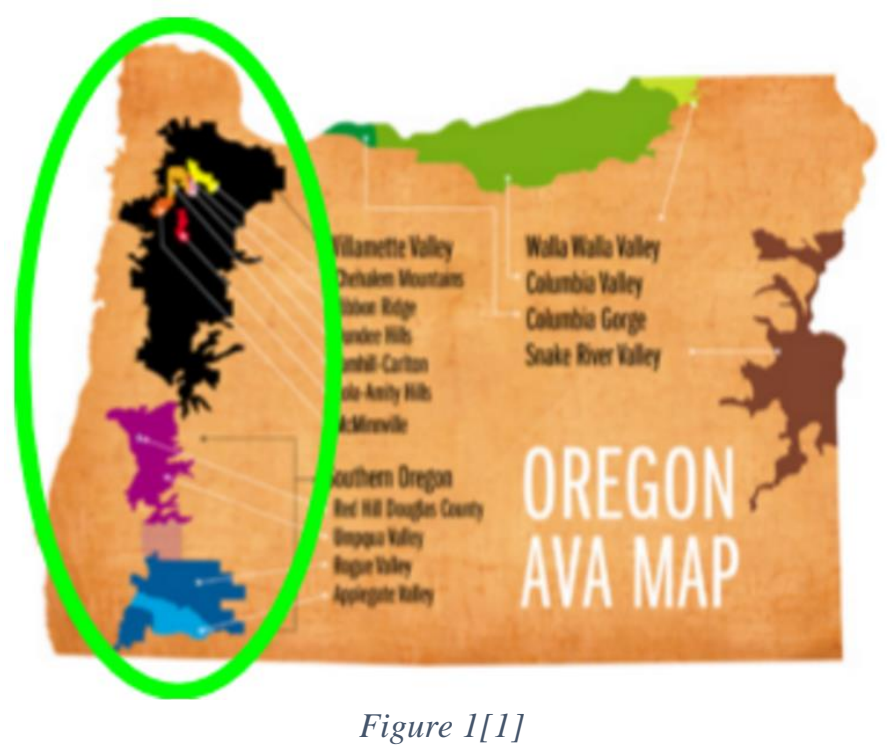


Grapes grow in very specific climates, and will not be able to thrive in any other kind of condition. The type of wines most commonly grown in Oregon are Pinot Noir and Pinot Gris, and those are the types of wines that will be most impacted by climate change because they grow well in cool climates (see figure 2). Figure 2 is a graph made by Dr. Greg Jones from the Southern Oregon University that outlines the ideal ripening temperatures for different grape types.

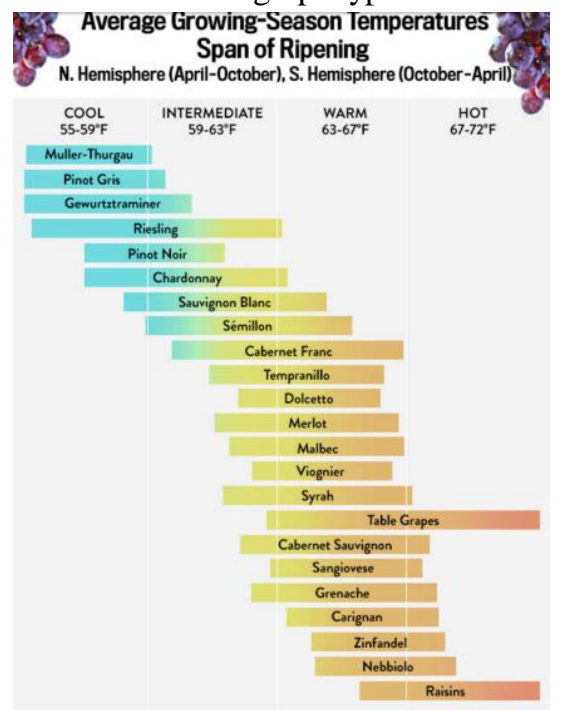

Figure 2 [1]

As can be seen in figure 2, Pinot Noir ideally ripens in in temperatures of $57 \mathrm{~F}$ to $61 \mathrm{~F}$. If the temperature is too cold then the grapes will not ripen at all, and if it is too hot the grapes become overripe and are not ideal to use for wine-making.

\section{Main Findings of Background Literature Survey on Oregon} Wine:

- Pinot Noir and Pinot Gris are the most valuable exports from the Oregon wine industry.

- The majority of the AVAs in Oregon are in Western Oregon, and more specifically in the Willamette Valley $(74 \%)$

- Pinot Noir ripens best in a temperature range of (57 F$61 \mathrm{~F})$.

- Pinot Gris ripens best in a temperature range of $(55 \mathrm{~F}$ - $60 \mathrm{~F})$

\section{Literature Survey about LOESS Curve Fitting Technique:}

NOAA uses a form of curve fitting called LOESS. This can be seen on the NOAA's State Annual and Seasonal Time Series website. LOESS is a curve fitting method often used in machine learning. It creates a smooth curve for a data set. It works by dividing the data into small, local subsets, and fitting those small subsets using first or second degree polynomials [9]. The length of these subsets is decided by the smoothing parameter which can be changed and set by the experimenter. A large smoothing value will lead to a curve that fluctuates less and is smoother. A small smoothing value leads to a curve that fluctuates more and matches the data set better [6]. However, a smoothing value too small will lead to the curve being influenced by small, meaningless variations in the data. The recommended settings for the smoothing parameter is 0.75 .

The way LOESS creates the polynomial equations for the small subsets of data is by using a weight function. This weight function is the tricube weight function, which gives higher weightage to data points near the point of estimation and less weightage to points that are farther away [6]. This equation is seen in equation 1 :

$$
w(x)= \begin{cases}\left(1-|x|^{3}\right)^{3} & \text { for }|x|<1 \\ 0 & \text { for }|x| \geq 1\end{cases}
$$

\section{Equation 1}

Main Findings of Background Literature Survey on LOESS Curve Fitting:

- Creates a smooth curve for a data set

- Breaks large set into subsets, and fits those small subsets with a one or two-degree polynomial equation.

- The size of these subsets are determined by the smoothing parameter.

- The weight function the LOESS uses the the tricube weight function, which weight points closer the point of estimation higher than points that are farther away.

\section{Previous Work}

Many articles have been written about the area that I aim to study. Many of these articles have interviewed, or are based on the work of Dr. Greg Jones. That being said, not many papers have been written on the topic that I am researching. There have been papers written on how climate change will affect Pinot Noir growth in other parts of the world, and papers about how climate change will affect the wine industry as a whole. The novelty of this project lies in its focus on a specific Pinot Noir growing region (Western Oregon). Also, unlike the many articles published on the internet, this project uses data mining techniques and data from NASA and the NOAA. Lastly, a comprehensive method of data analysis using LOESS curve fitting was used derive meaningful insights from the data.

\section{Methods}

To conduct this research, the first step was to get Western Oregon heat maps from NASA and the climate data for Oregon from NOAA. Then, using ImageJ, the heat maps were analyzed and data was extracted from them. Lastly, using R, LOESS was used to fit curves to climate and heat map data, and these LOESS curves were crucial in drawing conclusions from the data. 


\section{Oregon Wine Sales Figures}

To conduct this investigation, it is crucial to see just how important Pinot Noir is to the Oregon wine business. Figure 3 is a chart from 2012 that is from the form 10-k of Willamette Valley Vineyards INC. Here we can see that a large part of the Willamette Valley Vineyard's sales come from the sales of Pinot Noir. In fact, it is also stated on the form that $47 \%$ of the company's cases sold, were cases of Pinot Noir [12]. Since $74 \%$ of the vineyards in Oregon are in the Willamette Valley and $88 \%$ of Pinot Noir is also grown in the Willamette Valley, we can use the statistics provided by Willamette Valley
Vineyards to see what a huge part of the Oregon wine industry Pinot Noir is.

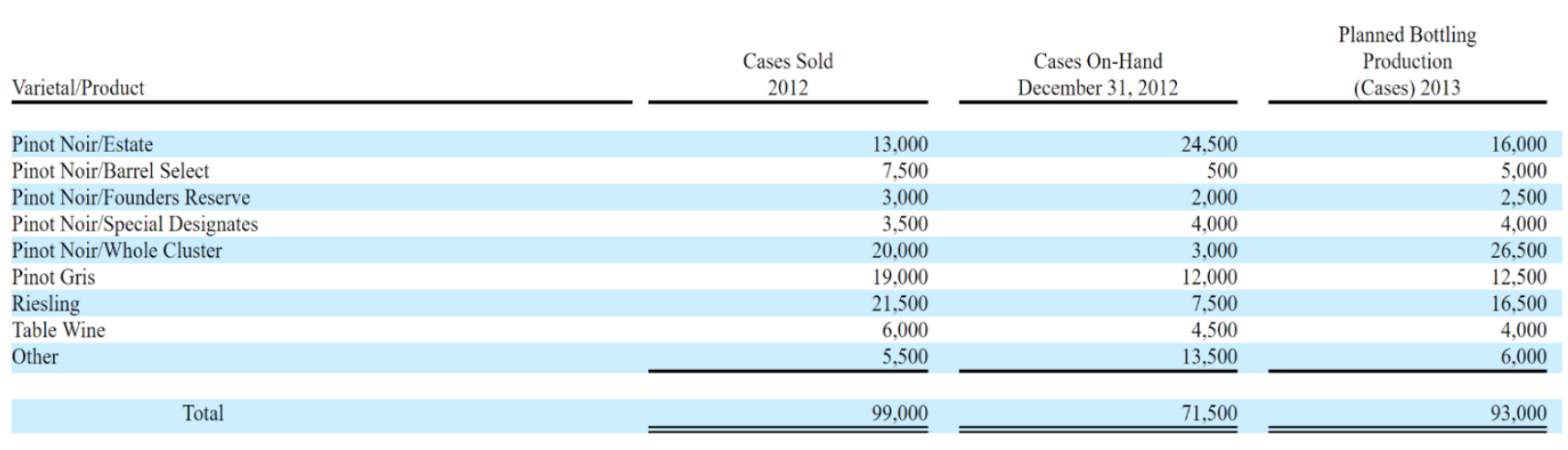

Figure 3 [12]

\begin{tabular}{|c|c|c|}
\hline Year & Oregon Avg Annual Temp (F) & $\begin{array}{l}\text { Area of Land in Western Oregon } \\
\text { within the ideal ripening temp for } \\
\text { Pinot Noir during the growing } \\
\text { season }\left(\mathrm{km}^{\wedge} \mathbf{2}\right)\end{array}$ \\
\hline 1979 & 46.9 & 60453.25 \\
\hline 1981 & 47.8 & 53983.21 \\
\hline 1984 & 45.63 & 50946.1 \\
\hline 1986 & 48.08 & 51359.53 \\
\hline 1989 & 46.47 & 64743.72 \\
\hline 1991 & 47.56 & 45397.4 \\
\hline 1994 & 47.83 & 54519.5 \\
\hline 1996 & 47.61 & 47487.52 \\
\hline 2000 & 47.39 & 62239.63 \\
\hline 2002 & 47.71 & 53743.83 \\
\hline 2004 & 48.39 & 54555.5 \\
\hline 2006 & 47.90 & 59566.88 \\
\hline 2009 & 47.19 & 55074.47 \\
\hline 2011 & 46.25 & 54009.38 \\
\hline 2013 & 47.56 & 56629.65 \\
\hline 2014 & 49.58 & 48743.28 \\
\hline 2015 & 50.4 & 49328.91 \\
\hline
\end{tabular}

Figure 4 (Data Table) Every data value in the rightmost column is the average of six data points, with each of the six data points representing one month of the growing season 


\section{Graph A}

Oregon's Average Annual Temperature vs. the Average Area of Land in Western Oregon during the Growing Season within the Ideal Temperature Range for Ripening Pinot Noir

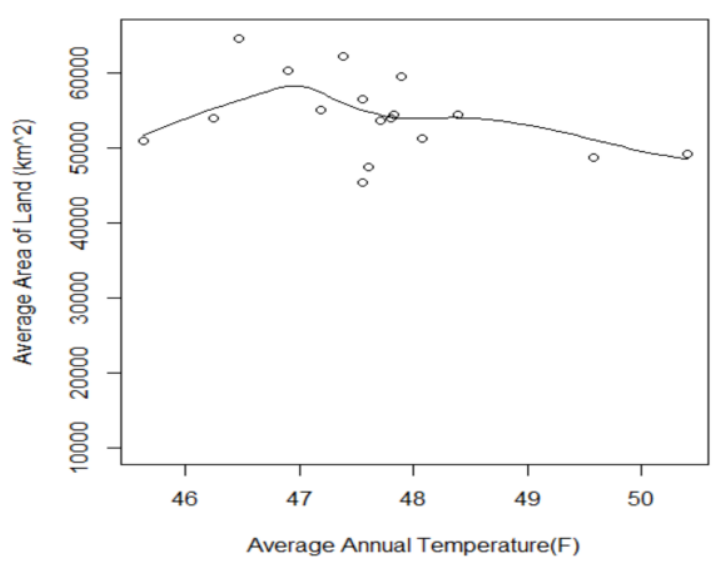

$\underline{\text { Graph B }}$

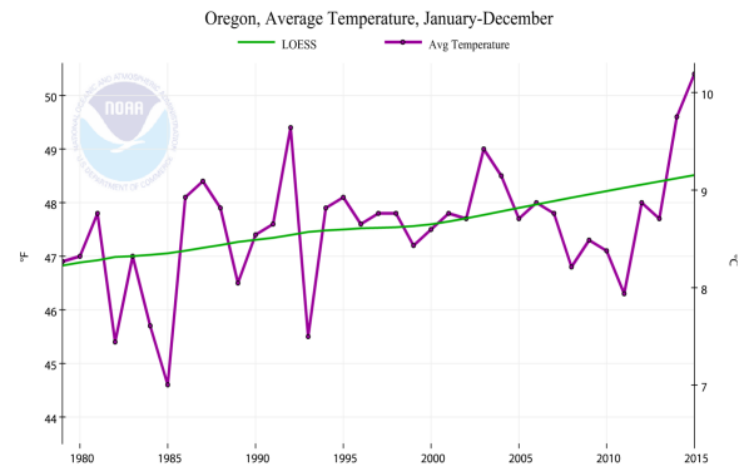

This graph is from the NOAA Climate at a Glance website

\section{Graph C}

Oregon's Average Annual Temperature vs. Time

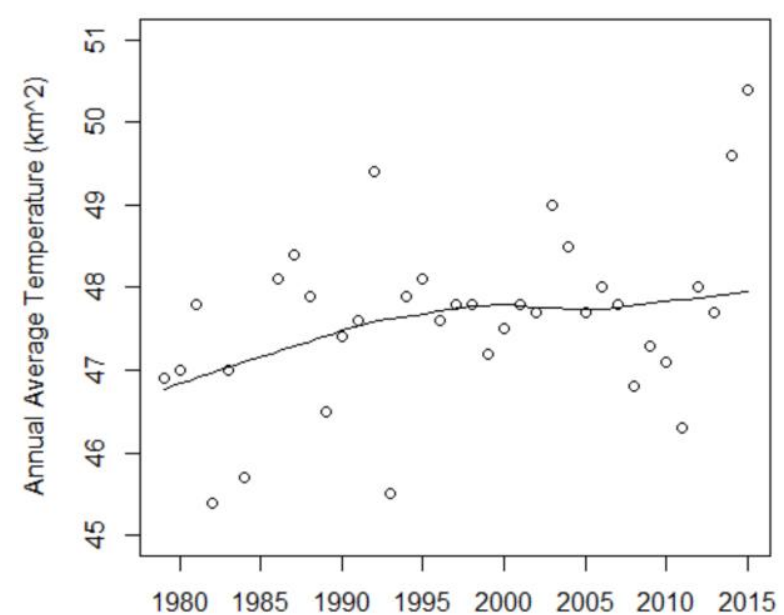

Year
Graph D

The Average Area of Land in Western Oregon during the Growing Season within the Ideal Temperature Range For Ripening Pinot Noir

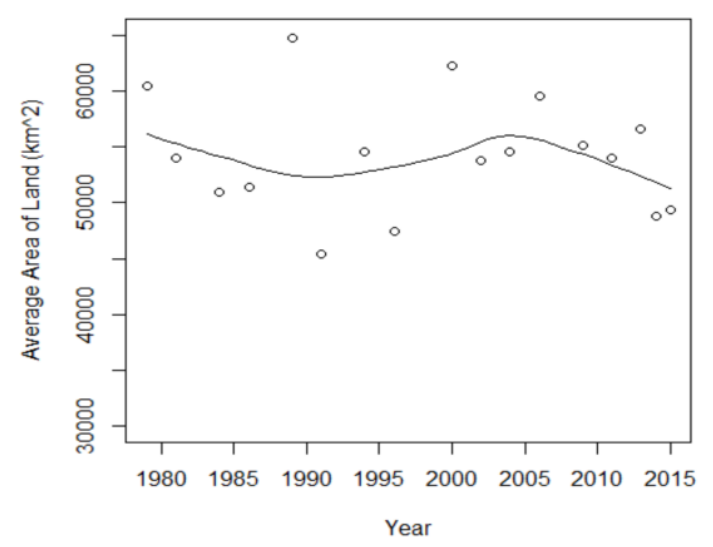

Western Oregon Heat Maps
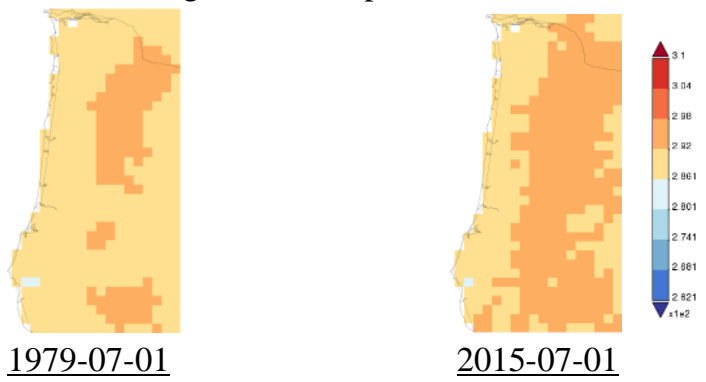

\section{Data Analysis}

In graph A it can be seen that the LOESS curve peaks around 47 degrees Fahrenheit. This means that the best annual average temperature to grow Pinot Noir is 47 degrees Fahrenheit. Graph A also shows that as the annual average temperature of Oregon increases or decreases beyond 47 degrees Fahrenheit, the area of land in Western Oregon within the suitable temperature range to ripen Pinot Noir also starts to decrease. The Pearson correlation coefficient for graph A is -0.372 , which means a $37 \%$ negative correlation. This means that the annual average temperature and the area of land with a suitable temperature for ripening Pinot Noir are negatively correlated. Also, the p-value for the data set that was graphed on graph $\mathrm{A}$ is 0.141 , which means about a $14 \%$ likelihood that this data occurred on accident. Usually a p-value of 0.141 is not considered to be statistically significant, but because the data set that was being worked with in this project had a high amount of variation, because of the many variables that affect the climate of a small area such as Western Oregon, a 0.141 p-value is acceptable.

Graph B is the original graph from NOAA and graph $\mathrm{C}$ is that same data except plotted in R. The LOESS curve on graph B shows that as time is passing, the average annual temperature of Oregon is rising. The Pearson correlation coefficient the data set graphed on graph B is 0.427 means a $42.7 \%$ positive correlation. This correlation is quite strong. The Pearson correlation coefficient shows that the passing of time 
and the annual average temperature of Oregon have a strong positive correlation. Lastly, the p-value of the data set graphed on graph B is 0.008 , which means that there was a $0.8 \%$ chance that this data was an accident. This p-value is definitely statistically significant.

Graph D is showing how the land with a suitable temperature to ripen Pinot Noir is decreasing over time. The LOESS curve on this graph does how a negative correlation. But the Pearson correlation coefficient is -0.122 which means a $12 \%$ negative correlation, which is very weak. Also, the p-value is extremely high at 0.639 . This means that there is a $64 \%$ chance that this data happened on accident. That is why the data on Graph D is not statistically significant and will have no effect on any conclusions drawn from this research.

On the Oregon heat maps the light-yellow color represents the land that has the ideal temperature for ripening Pinot Noir. Both the maps are taken in the same month, July, and they show visually that between 1979 and 2015 the area on land that has the ideal temperature for ripening Pinot Noir has decreased. In fact, the area of land that is light-orange, which represents land that is above the ideal temperature for ripening Pinot Noir, has increased significantly. These heat maps are from NASA's Giovanni website. However, the drastic decrease of land that is suitable for growing Pinot Noir that is seen on the heat maps is not actually how drastically the suitable land is decreasing. Overall, when all of the months of the growing season are averaged together, the decrease is very gradual. These heat maps are just serving the purpose of visualizing the research that has been done.

\section{Conclusion}

Graph A shows that as the average annual temperature of Oregon increases, the area of land that has the ideal temperature to ripening Pinot Noir decreases. Graph B and C show that as time passes the average annual temperature of Oregon is increasing. From this we can infer that as time passes, the area of land in Western Oregon during the growing season that has a suitable temperature for growing Pinot Noir will decrease.

Another big trend that can seen in Graph A is that the best average annual temperature to grow Pinot Noir is around 47 degrees Fahrenheit. This means that in years where Oregon's average annual temperature is near 47 degrees Fahrenheit, there will be the most area of land in Western Oregon during the growing season that has the ideal temperature for ripening Pinot Noir.

\section{Implications for Oregon Wine Industry}

The loss of land in Western Oregon in which Pinot Noir can be properly ripened would be big hit to the Oregon wine industry. This is because Pinot Noir is the most important grape for wine-making in Oregon. Also, most of the Pinot Noir in Oregon is grown in Western Oregon. This is why the loss of land suitable for properly ripening Pinot Noir in Western Oregon is particularly detrimental for Pinot Noir growth in Oregon as a whole.

\section{$\underline{\text { Caveat }}$}

This experiment looked at the area of land in the suitable temperature range for ripening Pinot Noir at a level that encompassed all of Western Oregon. Obviously, not all of Western Oregon is used for growing Pinot Noir. This means that the actual effects of climate change on Pinot Noir growth might have a different magnitude if the area of land that was looked at was entirely made up of wineries.

\section{Acknowledgements}

I would like to thank Dr. Robert Scheller from Portland State University for helping with and directing my research. I would also like to thank Dr. Gregory Jones from the Southern Oregon University for providing lots of valuable feedback to guide my research.

\section{$\underline{\text { Resources }}$}

1. "A Guide to Learning Oregon Pinot Noir." Wine Folly. N.p., 16 Sept. 2015. Web. 17 Feb. 2017. URL: http://winefolly.com/review/guide-to-oregonpinot-noir/

2. Shelton-Tiderman, Annette. "Quality Information, Informed Choices." Fruit of the Vine: Oregon's Grape and Wine Industry - Article Display - QualityInfo. N.p., n.d. Web. 17 Feb. 2017. URL:

https://www.qualityinfo.org/-/fruit-of-the-vineoregon-s-grape-and-wine-industry

3. Miller, Carrie. "Pinot Noir Is the Polar Bear of Wines." Slate Magazine. N.p., 23 Dec. 2014. Web. 17 Feb. 2017.URL:

http://www.slate.com/articles/technology/future_te nse/2014/12/wine_and_climate_change_pinot_noir _is_the_vintner_s_polar_bear.html

4. "Learn Your AVAs." Oregon Wine Press - dedicated to Oregon wine, pinot noir, food, vineyards, winemakers, and insider-industry happenings. N.p., n.d. Web. 17 Feb. 2017.URL: http://www.oregonwinepress.com/article?articleTi tle=learn+your+avas--1299023124--656--

5. Enloe, Ethen Shepherd Jesse. "State Annual and Seasonal Time Series." State Temperatures | Temperature, Precipitation, and Drought | National Centers for Environmental Information (NCEI). N.p., n.d. Web. 17 Feb. $2017 . \quad$ URL: https://www.ncdc.noaa.gov/temp-and-precip/statetemps/

6. Yau, Nathan. "How to: make a scatterplot with a smooth fitted line." FlowingData. N.p., 09 Feb. 2012. Web.17.Feb.2017.URL:

https://flowingdata.com/2010/03/29/how-to-makea-scatterplot-with-a-smooth-fitted-line/ 
7. Willems, Karlijn. "Machine Learning in $\mathrm{R}$ for beginners." DataCamp Community. N.p., n.d. Web. 17 Feb.2017.URL:

https://www.datacamp.com/community/tutorials/ machine-learning-in-r

8. "Annual Report for Fiscal Year 2015-2016." Oregon Wine Industry. N.p., n.d. Web. 17 Feb. 2017. URL: http://industry.oregonwine.org/about-the-oregonwine-board/annual-report/

9. Earl F., Glynn. "Loess Smoothing and Data Imputation." Loess Smoothing and Data Imputation. N.p., n.d. Web 17.Feb.2017.URL: http://research.stowers.org/mcm/efg/R/Statistics/l oess.htm

10. Bland, Alastair. "How Oregon's Prized Pinot Noir Grapes Will Take the Heat Of Climate Change." NPR. NPR, 11 Sept. 2012. Web. 17 Feb. 2017. URL: http://www.npr.org/sections/thesalt/2012/09/11/16 0957581/how-oregons-prized-pinot-noir-grapeswill-take-the-heat-of-climate-change

11. "LOESS Curve Fitting (Local Polynomial Regression)." LOESS Curve Fitting (Local Regression) - StatsDirect. N.p., n.d. Web. 17 Feb. 2017.

URL:

http://www.statsdirect.com/help/content/nonpara metric_methods/loess.htm

12. "Willamette_10k-15465.htm."Willamette_10k15465.htm. N.p., n.d. Web. 17 Feb. 2017. URL: https://www.sec.gov/Archives/edgar/data/838875/0 00119983513000141/willamette_10k-15465.htm

13. "When is Wine Harvest Season?" Wine Folly. N.p., 21 Mar. 2014. Web. 17 Feb. 2017. URL: http://winefolly.com/tutorial/start-planning-nowwine-harvest-season/

14. "Willamette Valley Vineyards Inc." WVVI Annual Income Statement - Willamette Valley Vineyards Inc. Annual Financials. N.p., n.d. Web. 17 Feb. 2017. URL: http://www.marketwatch.com/investing/stock/wvv i/financials 